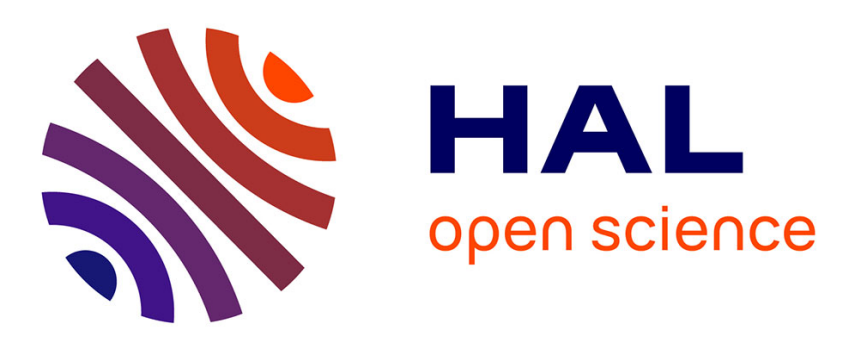

\title{
The $\mathrm{ZH}$ ratio method for long-period seismic data: sensitivity kernels and observational techniques
}

\author{
T. Tanimoto, Luis Rivera
}

\section{To cite this version:}

T. Tanimoto, Luis Rivera. The $\mathrm{ZH}$ ratio method for long-period seismic data: sensitivity kernels and observational techniques. Geophysical Journal International, 2008, 172 (1), pp.187-198. 10.1111/j.1365-246X.2007.03609.x . hal-03184912

\section{HAL Id: hal-03184912 \\ https://hal.science/hal-03184912}

Submitted on 18 Jun 2021

HAL is a multi-disciplinary open access archive for the deposit and dissemination of scientific research documents, whether they are published or not. The documents may come from teaching and research institutions in France or abroad, or from public or private research centers.
L'archive ouverte pluridisciplinaire HAL, est destinée au dépôt et à la diffusion de documents scientifiques de niveau recherche, publiés ou non, émanant des établissements d'enseignement et de recherche français ou étrangers, des laboratoires publics ou privés. 


\title{
The $\mathrm{ZH}$ ratio method for long-period seismic data: sensitivity kernels and observational techniques
}

\author{
T. Tanimoto ${ }^{1}$ and L. Rivera ${ }^{2}$ \\ ${ }_{1}^{1}$ Institute for Crustal Studies and Department of Earth Science, University of California, Santa Barbara, CA 93106, USA. E-mail: toshiro@geol.ucsb.edu \\ ${ }^{2}$ EOST-IPGS, 5 rue Rene Descartes, F67084 Strasbourg Cedex, France
}

Accepted 2007 Seotember 6. Received 2007 September 4; in original form 2007 June 21

\begin{abstract}
S UMMAR Y
Amplitude ratio between vertical and horizontal components of Rayleigh waves is controlled by structure beneath a seismic station. This ratio, measured as a function of frequency, has been extensively analysed for shallow crustal structure study in earthquake engineering and applied seismology. This quantity, termed the $\mathrm{ZH}$ ratio in this paper, may be useful for deep earth structure study and its feasibility for the frequency range between 0.004 and $0.05 \mathrm{~Hz}$ (period 20$250 \mathrm{~s}$ ) is explored in this paper. For depth sensitivity kernels, we demonstrate that a numerical approach is practical and provides sufficient accuracy for structural inversion. Depth extent of sensitivity kernels are about half of depth extent in phase velocity kernels, indicating that the $\mathrm{ZH}$ ratio is useful for studying the lithospheric structure. Two observational approaches for measurement of the $\mathrm{ZH}$ ratio are presented; the first approach uses simple envelope amplitude ratio and the second approach uses waveform correlation technique between vertical and horizontal components. The $\mathrm{ZH}$ ratio data alone only constrains structure beneath seismic stations but recent densification of seismic networks may make it possible to extend the analysis to regional scale structure. A greater opportunity may exist in combination of the $\mathrm{ZH}$ ratio method and the phase and group velocity measurements.
\end{abstract}

Key words: Surface waves and free oscillations; Wave propagation; Crustal structure.

\section{INTRODUCTION}

Proliferation of dense arrays of three-component seismographs is giving us new opportunities to probe the interior of the Earth. There are many approaches that can be devised to probe the Earth structure but surface waves remain an excellent source of information for the crust and upper mantle because of the way surface waves propagate through shallow structure. During the last two decades, we have seen many examples of successful application of phase and group velocity studies that illuminated the 3-D upper-mantle structure.

In this paper, we will explore a new surface-wave approach which examines the ratio of vertical to horizontal amplitudes in Rayleigh waves as a function of frequency. We refer to this parameter as the $\mathrm{ZH}$ ratio. The idea of using this ratio has been around a long time, perhaps the first being Boore \& Toksöz (1969). Boore and Töksoz examined the frequency band between 0.02 and $0.1 \mathrm{~Hz}$, but the use of this method has mainly focussed on higher frequency band since then; many researchers adopted this technique to clarify shallow crustal structure. The method is often referred as the H/V method and a partial list of contributors include Horike (1985), Yamanaka et al. (1994), Chouet et al. (1998), Scherbaum et al. (2003), Hinzen et al. (2004) and Tanimoto \& Alvizuri (2006). Okada (2003) provides a good summary of this line of work up until 2003.
Ferreira \& Woodhouse (2007) recently applied this approach for long-period Rayleigh waves (about $150 \mathrm{~s}$ ). They reported, mainly, the existence of large scatter in Rayleigh-wave ellipticity measurements, attributing its cause to small-scale structure in the Earth. Our results somewhat counters their conclusion in that we can obtain stable estimates. We do see fairly large scatter in measurements, as Ferreira $\&$ Woodhouse (2007) claimed, but we will show that stable estimates emerge after collecting statistics for many earthquakes.

In Section 2, we define the ZH ratio. We then show variations of this parameter for some earth models; there are fairly large variations among earth models for this parameter, mainly because this ratio is sensitive to shallow structure for which many earth models contain differences (such as Moho depths and thickness of sedimentary layers). In Section 3, our numerical approach to compute depth sensitivity kernels is presented and the differences from phase velocity kernels are shown. In Section 4, we present our two schemes to measure this ratio from global seismograph network data. We will show results for some specific stations and discuss our preference based on performance with real data. In Section 5, we present examples for some stations and comparison to some theoretical values for two earth models.

The main purpose of this paper is to point out that the $\mathrm{ZH}$ ratio may be a useful independent parameter to constrain Earth structure and to present measurement techniques for it. The next step is the 

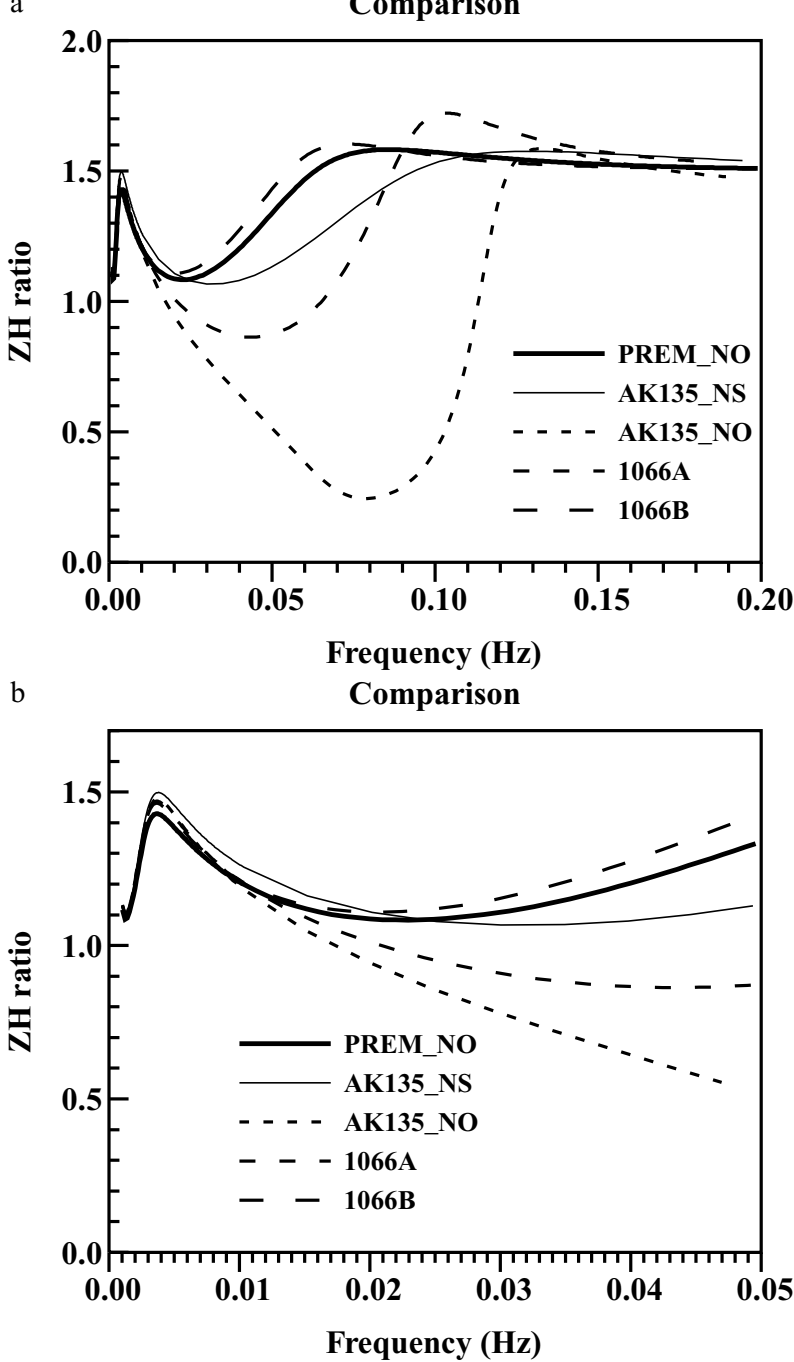

Figure 1. (a) The ZH ratio for five earth models. (b) The same with (a) except that this is an expanded plot for the frequency range $0-0.05 \mathrm{~Hz}$.

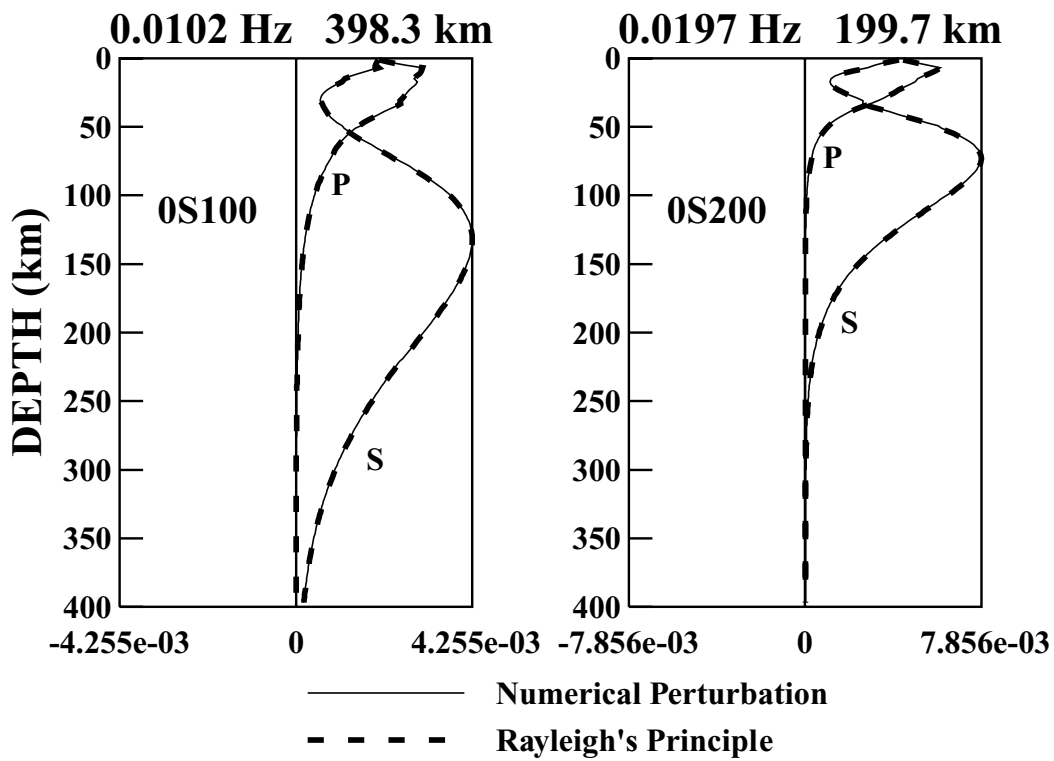

inversion of the $\mathrm{ZH}$ ratios for Earth structure which we plan to report later.

\section{ZH RATIO}

Suppose we collect Rayleigh wave data from many earthquakes at a seismic station and measure the ratio, $\eta$, of vertical to horizontal amplitudes:

$\eta(\omega)=\frac{Z(\omega)}{H(\omega)}$,

where the ratio is a function of frequency, $Z(\omega)$ is the vertical amplitude and $H(\omega)$ is the horizontal amplitude.

We use the horizontal amplitude in the denominator $(Z / H)$, the opposite of a typical $H / V$ method, because we have found that, for some frequency range, vertical amplitudes of Rayleigh waves can disappear in a realistic structure (Tanimoto \& Rivera 2005) and thus making the ratio $H / V$ infinite. By defining it inversely, the ratio is almost always finite and is easier to handle when inverting this parameter for Earth structure.

This parameter is the ratio of the two (vertical and horizontal) eigenfunctions of Rayleigh waves at the surface; since the eigenfunctions are determined by a local structure, this parameter is fixed for a station. Therefore, measurement for different earthquakes should show constancy of this value in all directions in an isotropic medium. In an anisotropic medium, the $\mathrm{ZH}$ ratios should show azimuthal dependence but they should remain constant for particular azimuths (of Rayleigh wave arrival).

Hereafter, we assume that the medium is isotropic. We examined the effects of anisotropy but scatters in $\mathrm{ZH}$ ratio measurements are too large to identify anisotropic signals in them.

Fig. 1(a) shows the $\mathrm{ZH}$ ratios for five earth models. The models PREM_NO and AK135_NO contain some modifications to the models; specifically the ocean in each model is replaced by structure below the ocean; we extended the crust upward and replaced the ocean. AK135_NS contains further modification from AK135_NO in that the top sedimentary layer is replaced by the crustal structure below this layer. For 1066A and 1066B, we used the values at sea bottom.

Figure 2. Comparison of analytical formulas and numerical difference scheme for phase velocity kernels. Accuracy of 3-4 digits are maintained by the numerical scheme. 

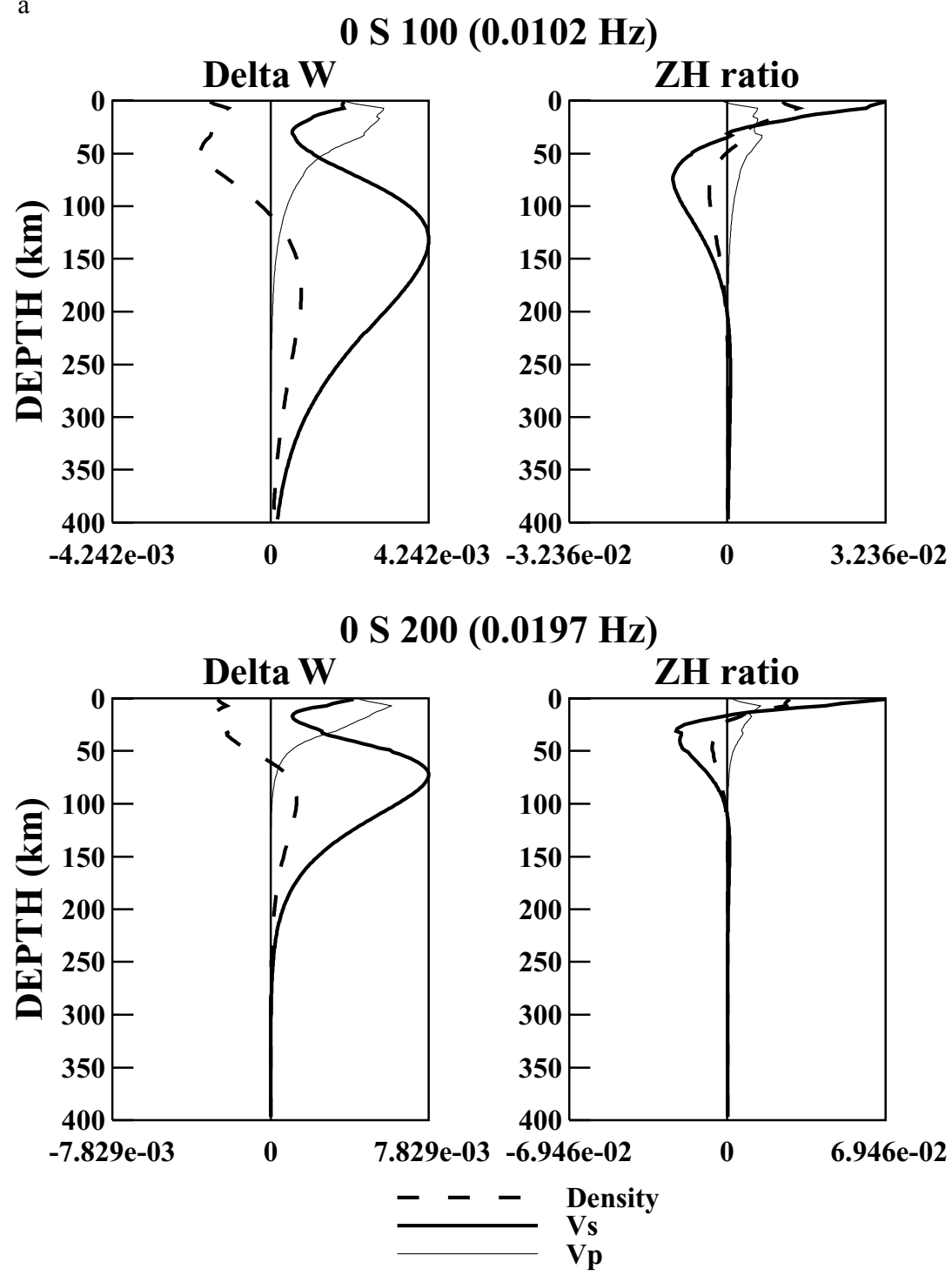

Figure 3. (a) Depth sensitivity kernels for ${ }_{0} S_{100}$ (top) and ${ }_{0} S_{200}$. Kernels for eigenfrequency perturbation (phase velocity) are shown on left and those for the $\mathrm{ZH}$ ratio are shown on right. (b) Depth sensitivity kernels for four modes. They are fundamental spheroidal modes and have similar shape.

What is striking in Fig. 1 are the differences among earth models for the $\mathrm{ZH}$ ratios. This seems to occur because the $\mathrm{ZH}$ ratio is generally sensitive to shallow structure and earth models tend to contain differences in shallow (crustal) structure. This point is underscored by AK135, which has a thick sediment; replacing this sedimentary layer by a typical crustal velocity makes the $\mathrm{ZH}$ ratios of this model much closer to other models but without these modifications, the $\mathrm{ZH}$ ratios of AK135 are quite different from other earth models.

Fig. 1(b) shows an expanded plot for frequencies up to $0.05 \mathrm{~Hz}$ (period $20 \mathrm{~s}$ ) and shows that the differences among earth models are evident at frequencies as low as $0.015 \mathrm{~Hz}$ (period $60 \mathrm{~s}$ ). Since surface wave data for global studies typically analysed from millihertz range up to about $0.03 \mathrm{~Hz}$, these results suggest that the $\mathrm{ZH}$ ratios may be useful for constructing a better reference earth model.

\section{DEPTH SENSITIVITY}

For the computation of depth sensitivity kernels, use of the Rayleigh's principle is the typical approach for phase and group ve- locity (Jobert 1956; Pekeris \& Jarosch 1958; Takeuchi 1959; Gilbert 1976; Woodhouse 1976; Woodhouse \& Dahlen 1978; Dahlen \& Tromp 1998). But since the $\mathrm{ZH}$ ratio is related to eigenfunctions rather than to eigenfrequencies, we have not been able to derive a compact formula. Instead, we opted to a numerical difference scheme (Tanimoto \& Alvizuri 2006).

Use of a numerical scheme could have two disadvantages in general; one is the potentially long computation time, because we need to perturb density, $P$-wave velocity and $S$-wave velocity separately at various depths and solve the eigenvalue problem for each case. But computers are now sufficiently fast that computation time is becoming less of a problem. The second disadvantage is the loss of precision problem that is inherently associated with numerical differentiation. In order to examine this point, we tested our numerical differentiation scheme against phase velocity estimates by Rayleigh's principle; comparison is shown in Fig. 2 by solid and dash lines and the two approaches yield very close results. In fact these results match only for about three digits, despite the similarities that are apparent in this figure. But our inversion tests 
b
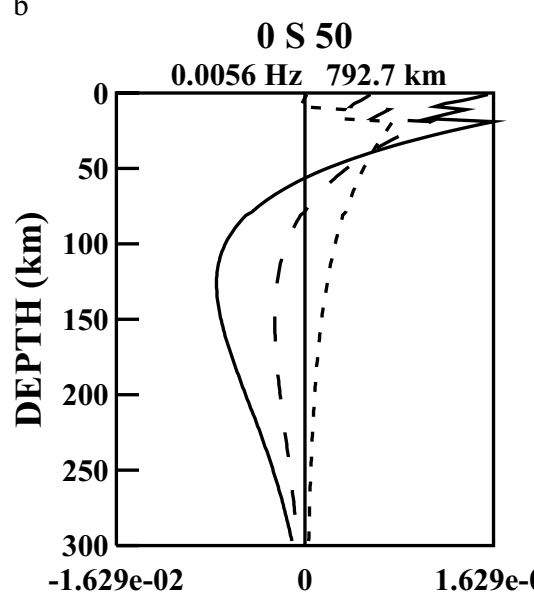

$0 \mathrm{~S} 250$

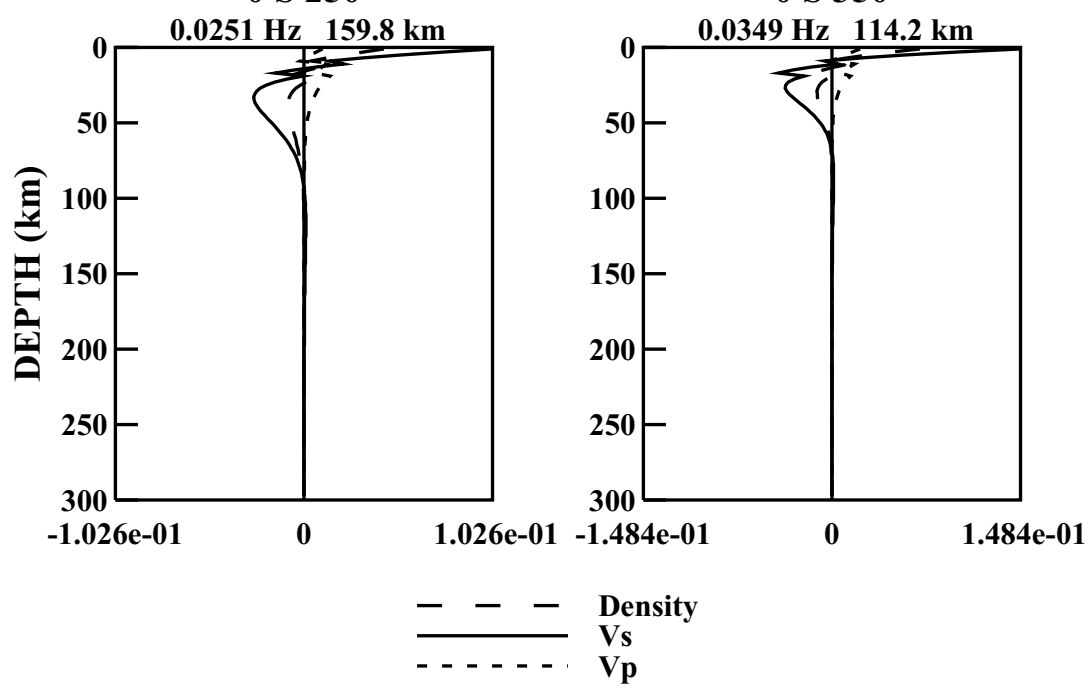

$0 \mathrm{~S} 150$

$0.0152 \mathrm{~Hz} 266.0 \mathrm{~km}$

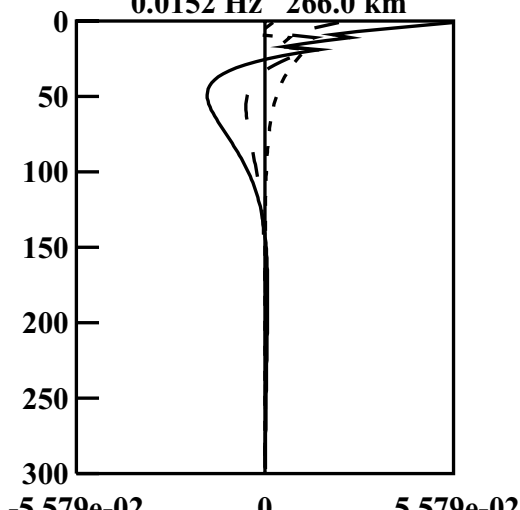

$\begin{array}{rrr}-5.579 \mathrm{e}-02 & 0 & 5.579 \mathrm{e}-02\end{array}$

0 S 350 in time intervals for estimating this ratio, especially by checking the phase shift between vertical and horizontal components. Scheme II uses a waveform correlation technique between vertical and horizontal components. We test and compare the two schemes using synthetic seismograms as data.

\subsection{Scheme I}

In this method, we first apply a narrow bandpass filter and compute the envelopes for vertical and horizontal components. Fig. 4 shows narrow bandpass-filtered synthetic seismograms for an earth model PREM (Dziewonski \& Anderson 1981) and their envelopes (dash). Three seismograms are shown at distances $20^{\circ}, 80^{\circ}$ and $140^{\circ}$; they were filtered between 10 and 14 millihertz $(\mathrm{mHz})$. More specifically,

and basically shrink vertically in depth as the eigenfrequencies increase. 
Distance $20 \mathrm{deg} \quad \mathbf{1 0 . 0 - 1 2 . 0 - 1 4 . 0}(\mathrm{mHz})$

$\mathbf{Z}$

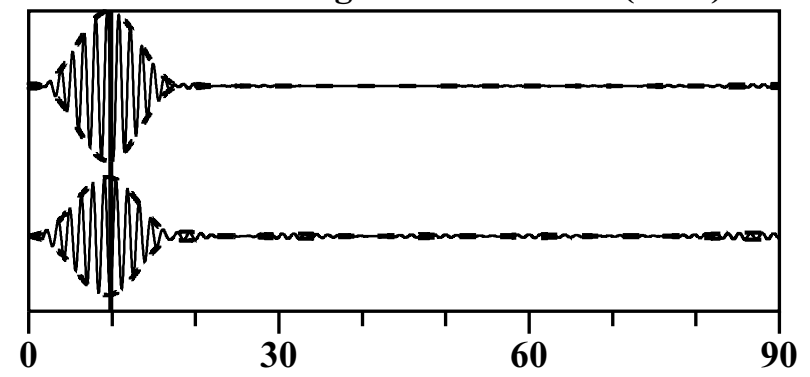

Distance $80 \mathrm{deg} \quad \mathbf{1 0 . 0 - 1 2 . 0 - 1 4 . 0}(\mathrm{mHz})$

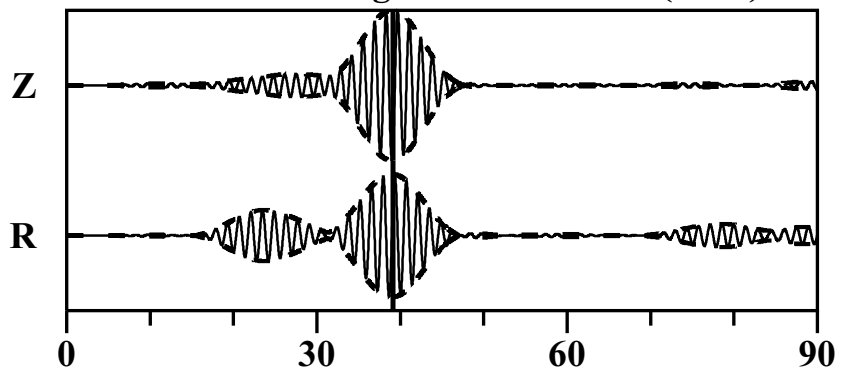

Distance $140 \mathrm{deg} \quad 10.0-12.0-14.0(\mathrm{mHz})$

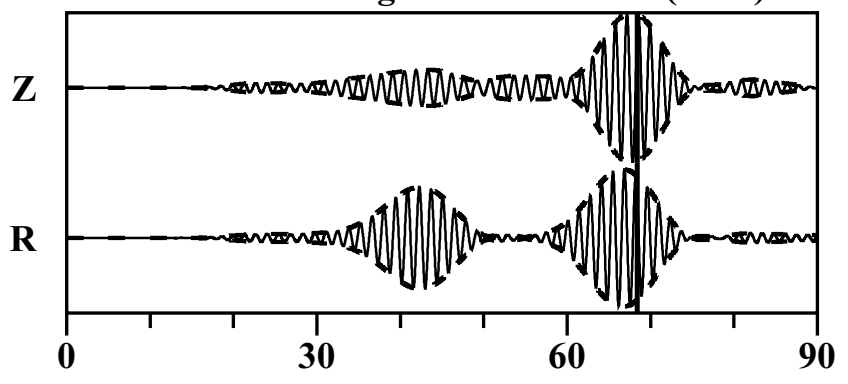

Time (minutes)

Figure 4. Synthetic seismograms for PREM at three distances. They are a part of data set used for testing the method. Envelopes are shown by dash lines.

this filter has the peak at $12 \mathrm{mHz}$ and taper on both sides of this peak by cosine functions (between 10 and 12 and between 12 and $14 \mathrm{mHz}$ ). Earthquake source depth is $52 \mathrm{~km}$ and thus fundamentalmode Rayleigh waves show the largest amplitudes in seismograms, although higher modes and body waves have some amplitudes as the seismograms at $80^{\circ}$ and $140^{\circ}$ show.

Using a group velocity window, we pick a time interval for fundamental-mode Rayleigh waves. Fig. 5 shows the case for distance $80^{\circ}$; vertical and radial component seismograms are shown in the top two panels. The third panel (from top) shows the ratio of envelopes between the two components as a function of time, although only the ratios between 0 and 2 are plotted in this panel. The bottom panel shows the phase shift between vertical and radial components (radial minus vertical) which should be $90^{\circ}$ for Rayleigh waves. Dash line in this panel indicates $90^{\circ}$ for comparison.

We carefully check the time interval that this phase shift is maintained; if the phase shift is within $90 \pm 5^{\circ}$, we indicated it by a thick line. Time interval of further analysis is determined from this phase shift information. Within this time interval, we use the ratios in the third panel and compute the mean and standard error of the $\mathrm{ZH}$ ratio.

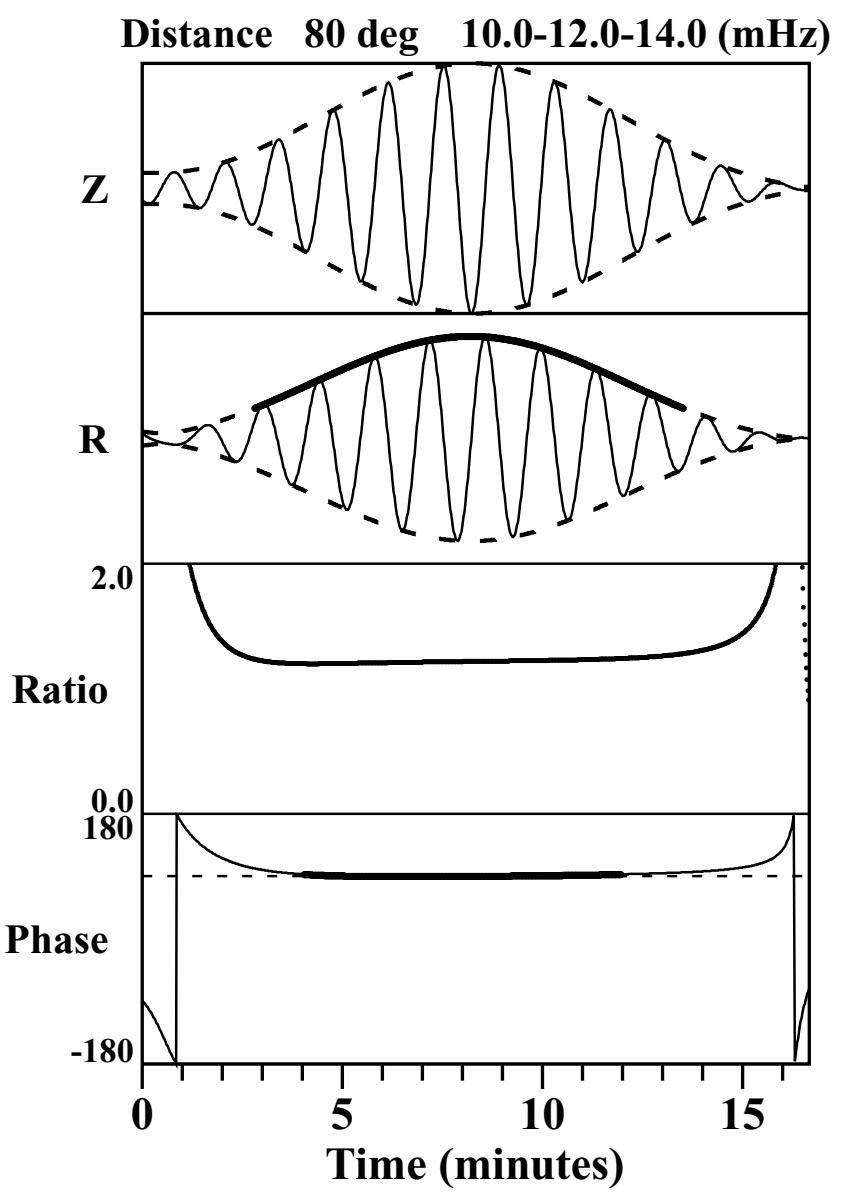

Figure 5. Scheme I measures amplitudes using the envelope after narrow bandpass filtering. Phase shift between the vertical and horizontal components are carefully checked in order to determine the time interval for the measurement of $\mathrm{ZH}$ ratio. Thick line in the bottom panel indicate the range that show $90 \pm 5^{\circ}$ in phase shift and this range is used to estimate the $\mathrm{ZH}$ ratio (from the third panel).

This approach seems to work well at many distances but we occasionally find a problem. One case is shown in Fig. 6 at a distance of $120^{\circ}$ (both top and bottom). For this synthetic seismogram, scheme I works fine for the top panel with high-frequency bandpass filter. A lower bandpass filter (bottom panel) shows a problematic case, caused by interference from an overtone phase (X waves). A major arc overtone phase, typically called X2 (e.g. Jobert et al. 1977; Tanimoto 1988), overlaps on the fundamental-mode phase from behind and makes it hard to estimate the amplitude of fundamentalmode Rayleigh waves accurately. More detailed information can be gained from Fig. 7(a). Envelopes shows distortion, especially the radial-component seismogram in this case. Phase shift is clearly not stable because of this interference and the ratio (the third panel) is also not constant for any time intervals. This kind of interference seems to be a major problem for this scheme.

Even at the same location, however, the $\mathrm{ZH}$ ratio can be successfully measured in higher frequencies (Fig. 7b); Fig. 7(b) is the case for the time series in Fig. 6(a) and the effect of higher mode phase is not a problem in this frequency band.

The case in Figs 6-7 indicates that it is difficult to automate this scheme. It may be possible if we incorporate waveform correlation or envelope correlation and detect interference from other phases. This has led to the development of scheme II. 


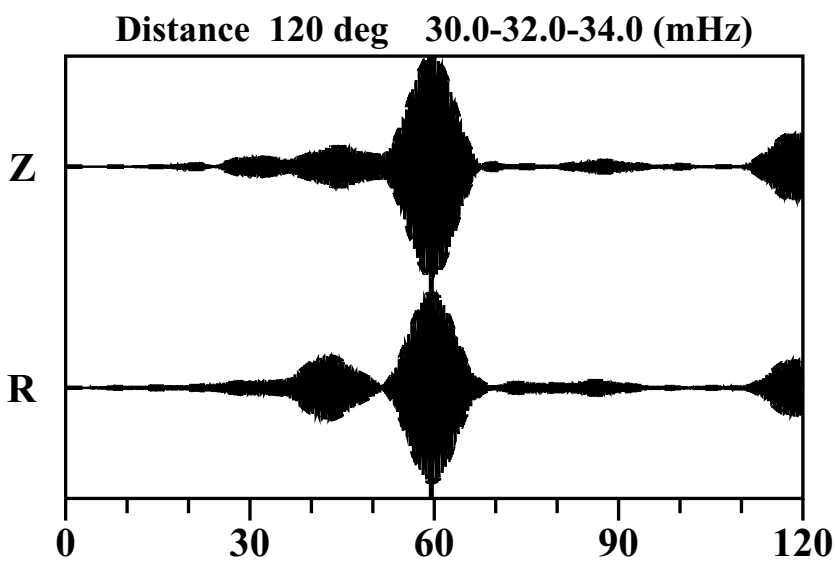

6.0- 8.0-10.0 (mHz)

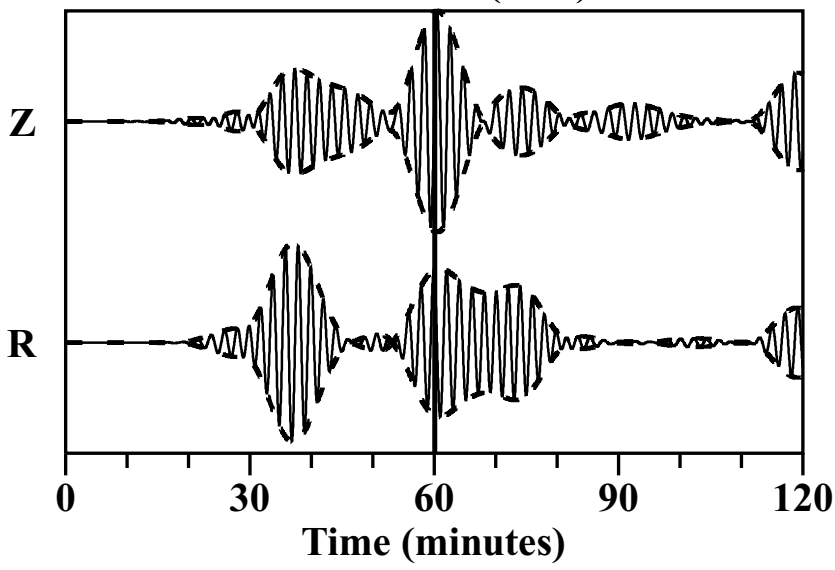

Figure 6. Some data show no problem in one frequency range but a serious problem in another. The bottom panel shows interference from the higher mode phase X2 that overlaps with the fundamental mode phase.

\subsection{Scheme II}

The second scheme also takes advantage of the fact that the radial component has 90-degree phase advance with respect to the vertical component. Figs 8(a)-(d) show examples from real data and show filtered seismograms at top and phase differences between vertical and horizontal components at bottom. Note that discussion for the scheme I, from Figs 4 to 7(b), dealt with synthetic seismograms but we now analyse real data with noise.

The method proceeds in the following way; we first apply a narrow bandpass filter. In the case of Fig. 8(a), the filter is centred at $0.025 \mathrm{~Hz}$ with tapers on both sides. We then take the vertical component seismogram and apply a 90-degree phase advance. If the data are Rayleigh waves, this phase-advanced (vertical-component) waveform should match the horizontal component waveform in phase. And amplitudes should provide information on the $\mathrm{ZH}$ ratio. The time series denoted by dash lines in the radial and transverse components are this phase-advanced seismogram. A good waveform match is confirmed for the radial component and lack of signal in the transverse component indicates that this wave packet has the retrograde particle motion. In other words, we confirm that this wave packet is the Rayleigh waves. A large amplitude phase in the transverse component at the beginning of the time series is Love waves.

We now replace the phase-shift criterion in scheme I by the criterion on the correlation coefficient between phase-advanced vertical

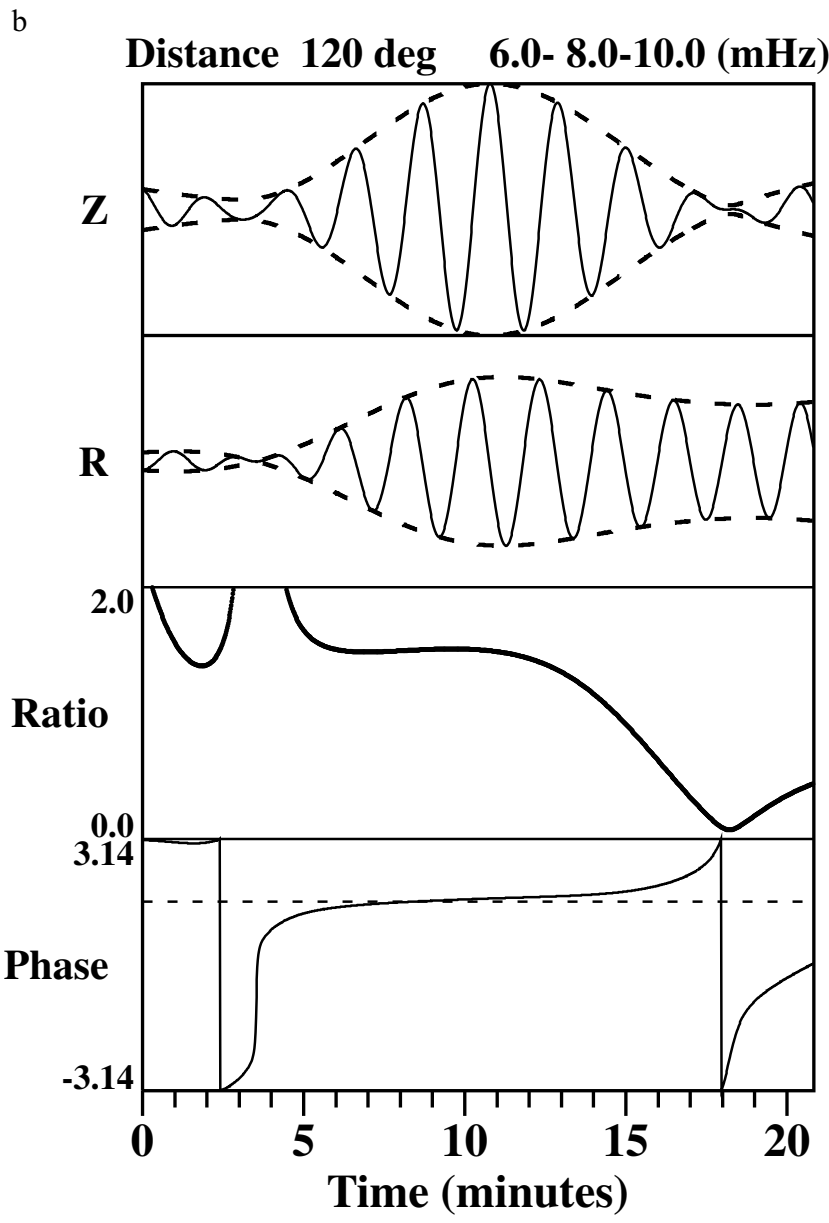

Figure 7. (a) Detailed analysis for the data in Fig. 6(b) shows serious problems; phase shift deviates from $90^{\circ}$ and the ratio of amplitudes is not constant for any time interval. (b) Despite the problem in low frequency range, the $\mathrm{ZH}$ ratio can be measured successfully at the same station (This is for the data in Fig. 6a).

component and horizontal component. We discard the data unless this correlation coefficient is larger than 0.9 . If this criterion is satisfied, we compute the amplitude ratio of the two phases which is the $\mathrm{ZH}$ ratio. This value is regarded as the measurement at $0.025 \mathrm{~Hz}$ in this case, the central frequency of the filter. We then slide filter parameters and obtain the $\mathrm{ZH}$ ratios at different frequencies.

We found that phase-shift deviations from $90^{\circ}$ in scheme II often turns out to be larger than $\pm 5^{\circ}$ (Fig. 8a, bottom panel). But a good waveform correlation assures us that the data are Rayleigh waves and the $\mathrm{ZH}$ ratio can be measured reliably. Another similar example to Fig. 8(a) is shown in Fig. 8(b), although this is at a lower frequency $0.015 \mathrm{~Hz}$.

In some cases, Rayleigh waves show off-great circle propagation and the arrival azimuth deviates from a great circle direction. Such an example is shown in Fig. 8(c). This does not pose a problem for scheme II, however, because the phase in the transverse component should be in phase with the radial component (if they were Rayleigh waves) and correlate well with the phase-advanced vertical component seismogram. If they correlate, it indicates the wave packet propagated along a path deviated from a great circle path. In scheme II, it is simple to estimate relative amplitudes of radial and transverse component and the direction of arrival. After correcting for this new angle, we derive the $\mathrm{ZH}$ ratio. Therefore, for all data, we 
Distance $120 \mathrm{deg} \quad 30.0-32.0-34.0(\mathrm{mHz})$

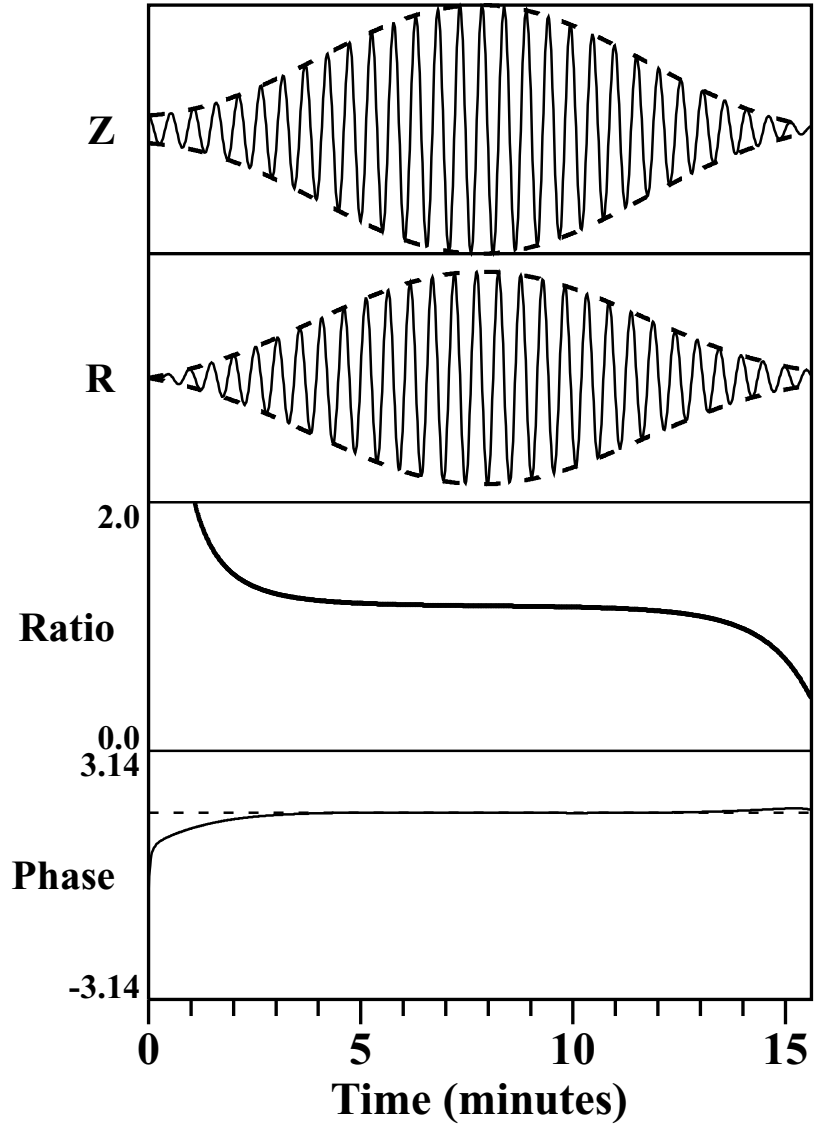

Figure 7. (Continued.)

examine the correlation not only between the (phase-advanced) vertical and radial component but also between vertical and transverse component.

Fig. 8(d) shows a case that, even though the data were filtered at high frequency, the effect of off-great circle propagation was not significant. We show this case in order to stress that not all highfrequency data require rotation of horizontal components.

\subsection{Comparison of two schemes}

Figs 9(a) and (b) show our synthetic tests for the two schemes we described above. Results at five distances are shown, although tests were performed at much finer interval for distance. Theoretical values for PREM are shown by solid lines.

Performance of the two schemes are very similar for these synthetic data and seems to work well overall, as most points are on the theoretical curves. However, both schemes show problems at short and long distances. At a short distance $\left(20^{\circ}\right)$, there is a hint of oscillations about the theoretical values. This is probably because of body waves which interfere Rayleigh waves in the analysis.

These test results also show some problems at a long distance $\left(140^{\circ}\right)$. This is again because of interference from other phases. This interference problem seems very difficult to solve in our approach. This is especially true for long-distance propagations as many different type of phases could interfere Rayleigh waves.

Generally speaking, however, we get very good match between our estimates and theoretical results for PREM, especially for a
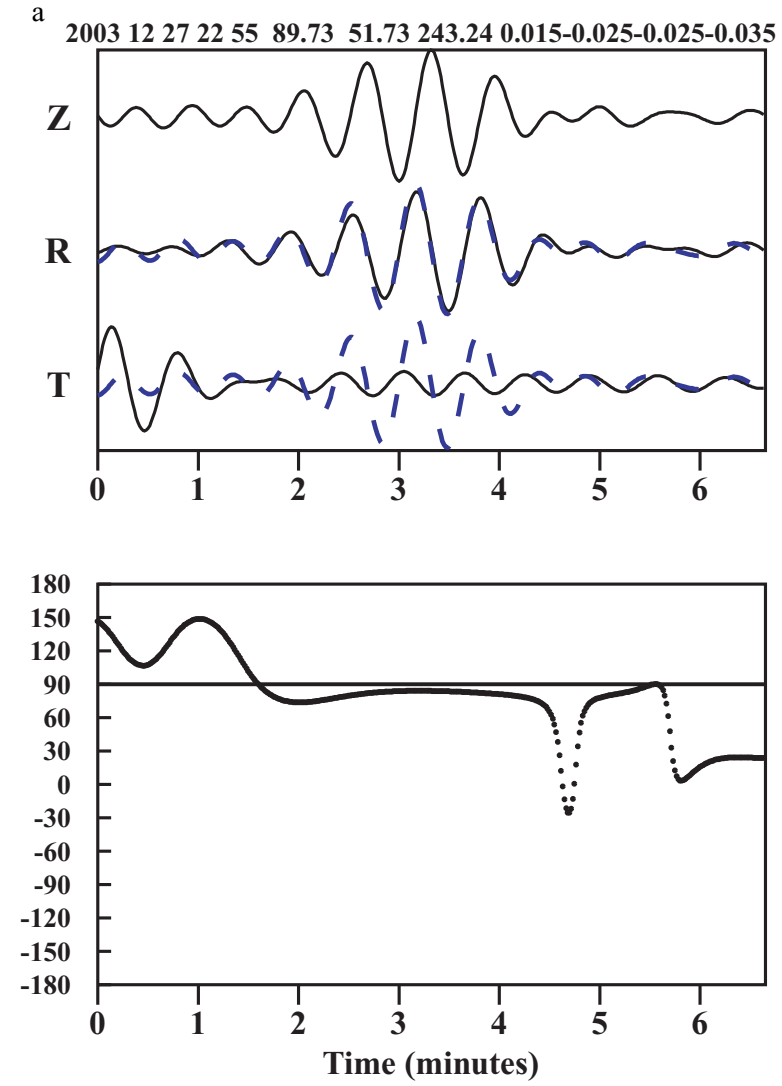

b
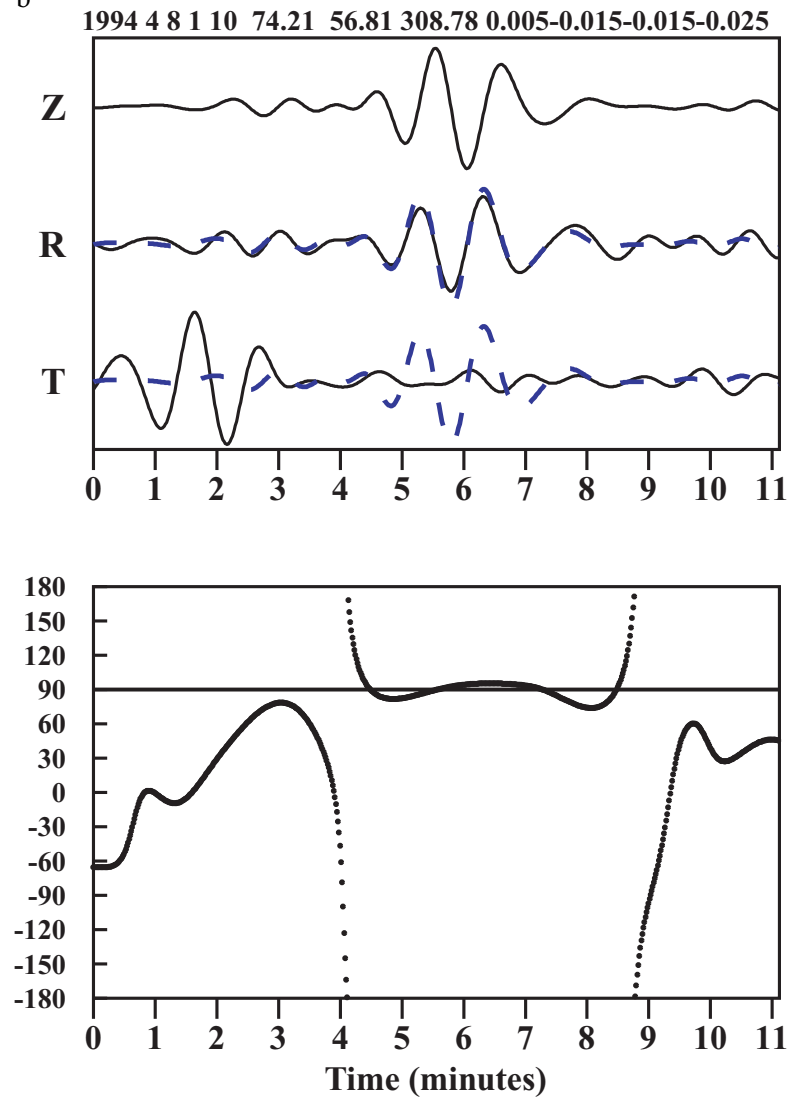

Figure 8. (a)-(d) Performance of scheme II for real data. Waveform correlation allows us to check off-great circle path propagation and potential interference from other phases. 
c
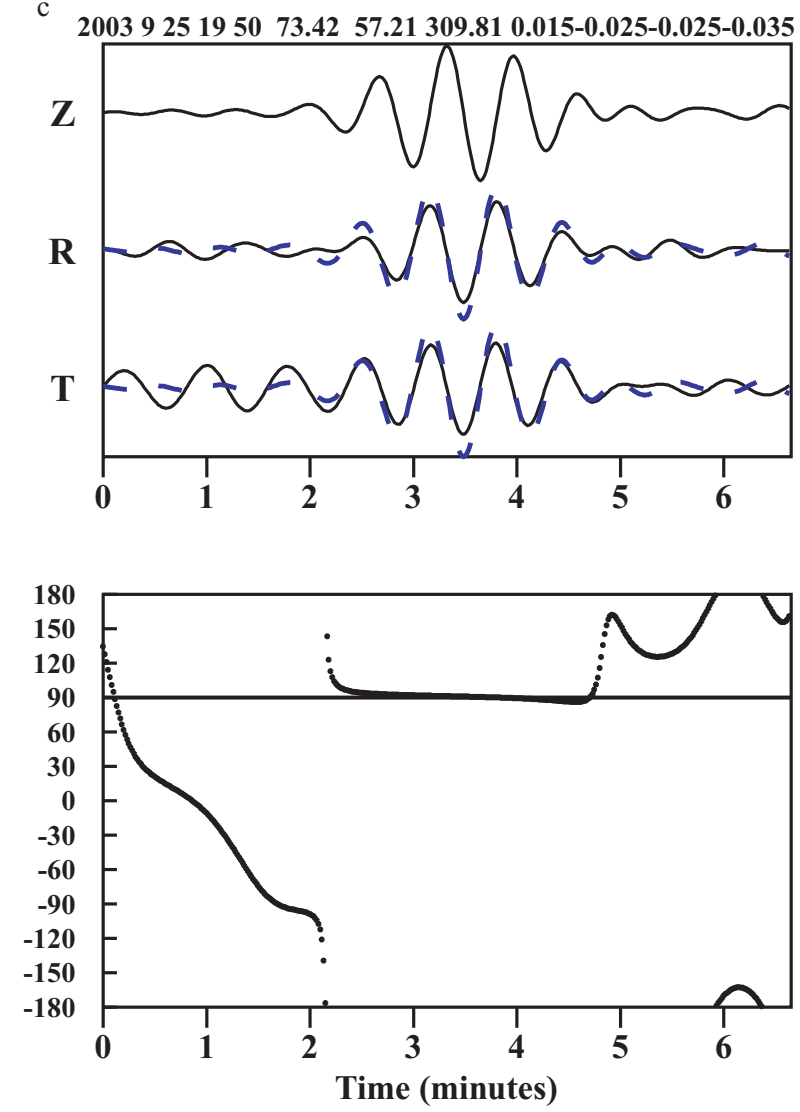

d
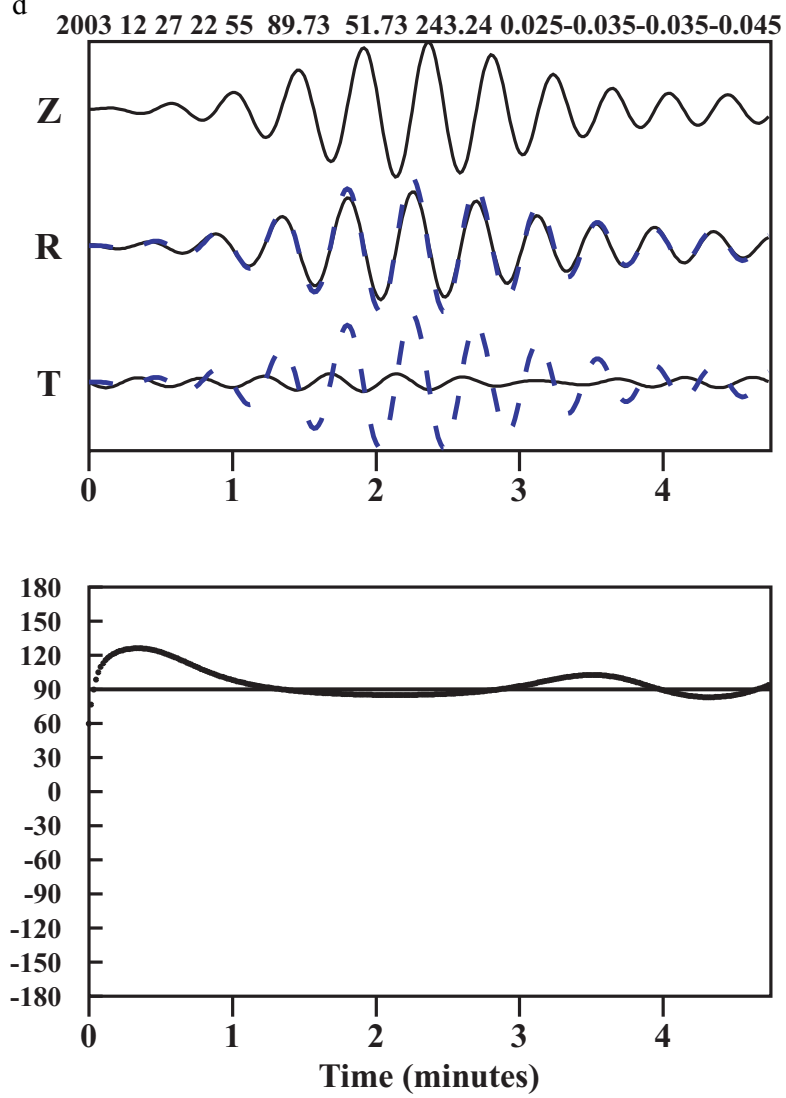

Figure 8. (Continued.)
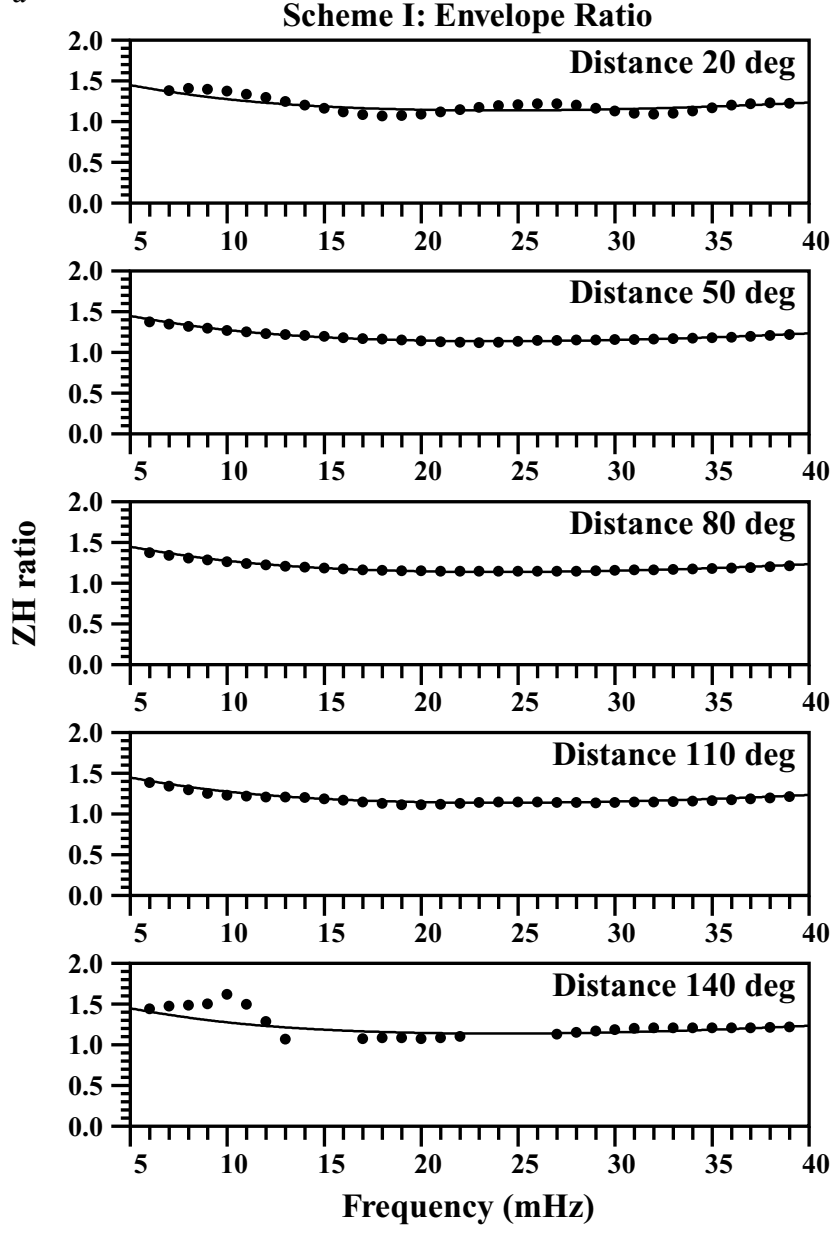

Figure 9. (a)-(b) Results of synthetic tests for scheme I (9a) and scheme II (9b). Performance of the two schemes are similar for this data set. Both indicate problems at a short distance $\left(20^{\circ}\right)$ and a long distance $\left(140^{\circ}\right)$. They are due to interference from body waves and higher-mode phases. We only use data between $40^{\circ}$ and $120^{\circ}$ for the analysis fo real data.

distances between $40^{\circ}$ and $120^{\circ}$. Therefore, in the analysis of real seismograms, we decided to use data for distances between $40^{\circ}$ and $120^{\circ}$ only.

We also compared the two schemes using real data. Figs 10(a) and (b) show examples from PAS (Pasadena in Southern California). We plot our results (ZH ratios) for all earthquakes larger than moment $5 \times 10^{18}(\mathrm{~N} \mathrm{~m})$ between 1988 and 2003. Results by scheme I (Fig. 10a) and those by scheme II (Fig. 10b) are shown for frequencies between 4 and $50 \mathrm{mHz}$. In this plot, the $\mathrm{ZH}$ ratio is taken in the horizontal axis and the frequency is taken vertically. What are shown are the statistics (counts) of measured $\mathrm{ZH}$ ratios within each bin of width 0.05 . Using these results (statistics), the mean and standard error of the $\mathrm{ZH}$ ratios were computed (numbers given on right in the figure). At each frequency, a narrow bandpass filter with tapering width $0.01 \mathrm{~Hz}( \pm 0.01 \mathrm{~Hz})$ were used.

Estimates by the two schemes match quite well as Figs 10(a) and (b) show. But there seems to be an important difference in statistical distributions of results; clearly results are much more smooth and Gaussian-like by scheme II than by scheme I. The main reason for this difference seems to be in selection criteria; the phase shift criterion in scheme I seems to have eliminated much more data than 
$\mathrm{b}$
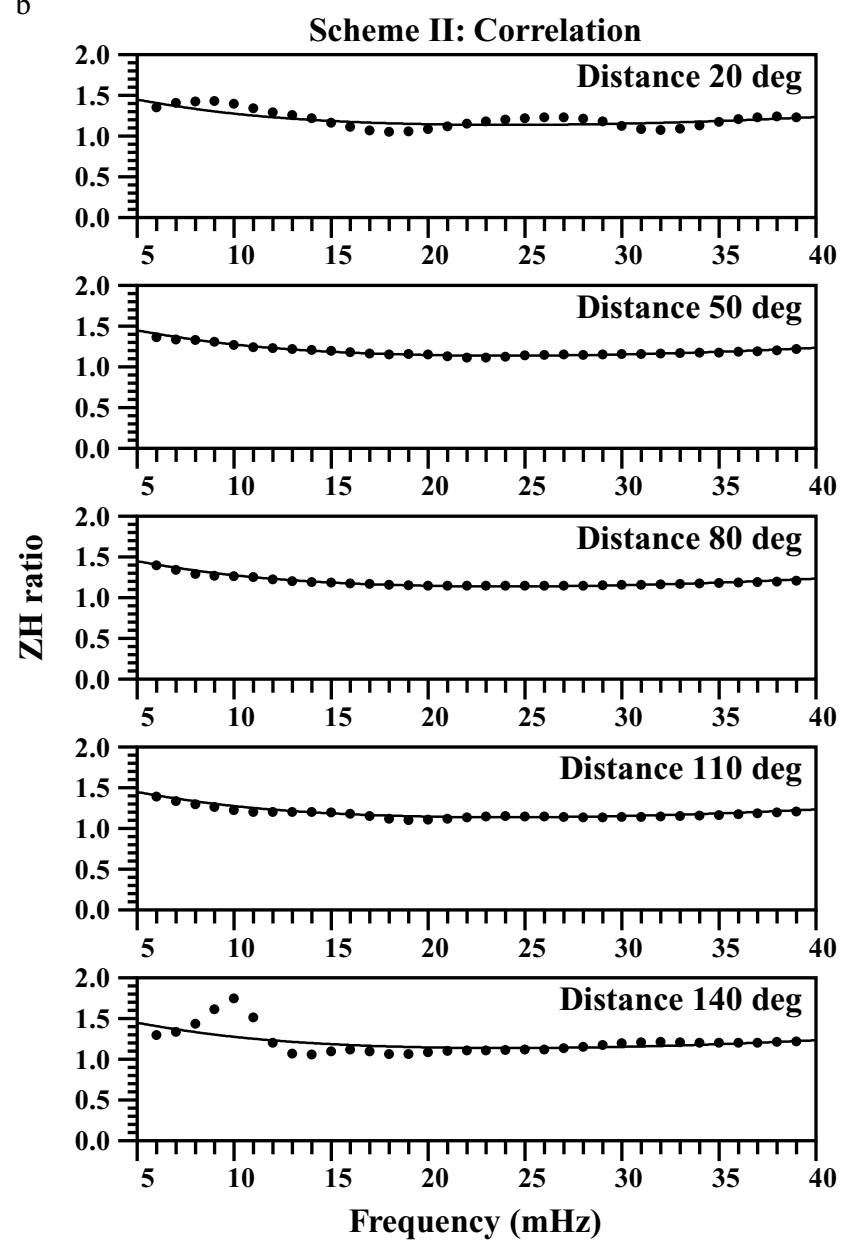

Figure 9. (Continued.)

the waveform correlation criterion in scheme II. Since the results by scheme II did not introduce any erratic distribution by incorporating more data, we tend to prefer the scheme II. We believe that it may be possible to tinker the criterion in scheme I to get equivalent results, but application of scheme II seems much more straightforward.

\section{COMPARISON WITH THEORETICAL VALUES}

We applied the above methods to stations in Southern California, especially the stations that have broadband instruments for long period of time. Results at five stations, derived by scheme II, are shown in Figs 11(a)-(e). In each case, we also plotted theoretical curves for two different earth models for comparison, PREM and AK135 (with some modifications to shallow structure). Observed data (solid circles) are shown with one-sigma error bars.

Perhaps the most notable features in these plots are the deviations of measured values from theoretical curves. Note that all stations are in Southern California and wavelength at the lowest frequency $(0.004 \mathrm{~Hz})$ are so large that the stations may not be considered far apart. But the $\mathrm{ZH}$ ratios seem to differ clearly from station to station. Deviations are seen in different frequency bands; for example, high frequency data show some large deviations for PAS and SNCC but the results at PHL seem to show almost con- stant shift in value for all frequencies. Clearly, these characteristics indicate differences in local structure, probably at quite shallow depths.

One of the most critical information for the success of the $\mathrm{ZH}$ ratio method is the instrument response for all three components. This is not necessarily easy because our proposed technique requires data for many earthquakes, instrument calibration information over many years must be reliable. We are aware that some long-term problems, say for STS-1 instruments, are documented by some researchers (e.g. Ekstöm et al. 2006). Clearly, regular monitoring of calibration information is needed for the success of this approach.

\section{CONCLUSION}

The $\mathrm{ZH}$ ratio is a parameter of Rayleigh waves, independent from phase and group velocity. They can be measured for seismic stations, equipped with three-component seismographs. The $\mathrm{ZH}$ ratios are typically sensitive to shallow structure in comparison to phase and group velocity that have dominated the analysis of Rayleigh waves. While compact formulas are not available for depth sensitivity kernels, they can be computed using a numerical difference scheme without any difficulty.

We developed two schemes to measure this ratio and applied it to real data. Our preferred method is the one that uses the waveform correlation between a phase-advanced vertical component seismogram and a horizontal component seismogram. This method can detect off-great path propagation and apply correction for it in the course of its application. Synthetic tests show excellent recovery of theoretical $\mathrm{ZH}$ ratio values. Although Ferreira $\&$ Woodhouse (2007) reported some difficulties in measuring the $\mathrm{ZH}$ ratio due to large scatters, we have shown that making statistics from many events allows us to make stable estimates for this parameter.

Examples of measurements were presented for some broadband stations in Southern California. Comparison with theoretical values for PREM adn AK135 show frequency-dependent deviations that vary from station to station. Such frequency dependent deviations are signals that can be inverted for underlying seismic structure and provide us an opportunity to improve Earth structure under each station. Recent dense arrays may make it possible to explore regional scale structure.

\section{ACKNOWLEDGMENTS}

This study was partly supported by NSF EAR-0408742 and by the Southern California Earthquake Center (SCEC). SCEC is funded by NSF cooperative Agreement EAR-0106924 and USGS Cooperative Agreement 02HQAG0008. The SCEC contribution number for this paper is 1118. The first author (T. Tanimoto) appreciates visiting professorship at Strasbourg when this project was started.

\section{REFERENCES}

Boore, D. \& Toksöz, M.N., 1969. Rayleigh wave particle motion and crustal structure, Bull. seism. Soc. Am., 59, 331-346.

Chouet, B., De Luca, G., Milina, G., Dawson, P., Martini, M. \& Scarpa, R., 1998. Shallow velocity structure of Stromboli Volcano, Italy, derived from small-aperture array measurements of Strombolian tremor, Bull. seism. Soc. Am., 88, 653-666.

Dahlen, F.A. \& Tromp, J., 1998. Theoretical Global Seismology, Princeton University Press, Princeton, New Jersey. 
a

PAS 1988-2003 Mo $>5.0 \mathrm{e}+18$ f_width $=0.0100$ Scheme 1

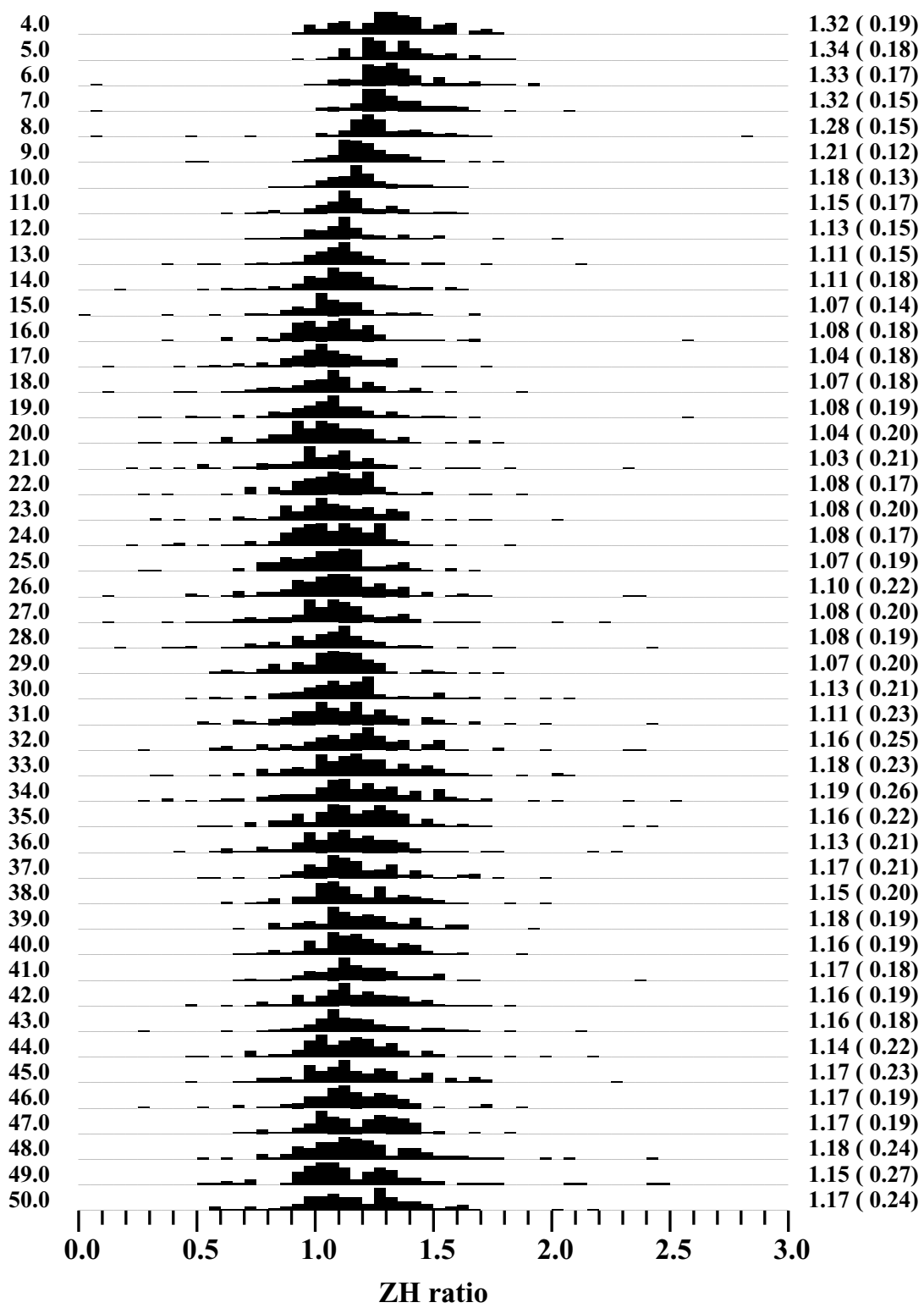

Figure 10. (a)-(b) The ZH ratio measured for PAS using all earthquakes larger than $5 \times 10^{19} \mathrm{~N} \mathrm{~m}$ in moment from 1988 to 2003 . The vertical axis is frequency and the horizontal axis is the ZH ratio. The number of measured ZH ratio in each bin (width 0.05) is shown. Scheme II seems to provide smoother Gaussian like distribution than scheme I.

Dziewonski, A.M. \& Anderson, D.L., 1981. Preliminary Reference Earth Model, Phys. Earth planet. Int., 25, 297-356.

Ekstöm, G., Dalton, C.A. \& Nettles, M., 2006. Observations of timedependent errors in long-period instrument gain at global seismic stations, Seism. Res. Lett., 77(1), 12-22.

Ferreira, A. \& Woodhouse, J.H., 2007. Observations of long period Rayleigh wave ellipticity, Geophys. J. Int., 169, 161-169, doi:10.1111/j.1365246X.2006.03276.x.

Gilbert, F., 1976. Differential kernels for group velocity, Geophys. J. R. astr. Soc., 44, 649-660.

Hinzen, K.-G., Weber, B. \& Scherbaum, F., 2004. On the resolution of H/V measurements to determine sediment thickness, a case study across a normal fault in the lower Rhine Embayment, Germany, J. Earthq. Eng., 8, 909-926.

Horike, M., 1985. Inversion of phase velocity of long-period microtremors to the $\mathrm{S}$-wave velocity structure down to the basement in urbanized areas, J. Phys. Earth, 33, 59-96.

Jobert, N., 1956. Evaluation de la periode d'oscillation d'une sphere heterogene par application du principe de Rayleigh, Comptes Rendus Acad. Sci. Paris, 243, 1230-1232.

Jobert, N., Gaulon, R., Dieulin, A. \& Roult, G., 1977. Sur des ondes a tres longue periode, caracteristiques du manteau superieur, Comptes Rendus Acad. Sci. Paris, 285, ser. B-49.

Okada, H., 2003. The Microtremor Survey Method, in Geophysical Monograph Series, Number 12, Society of Exploration Geophysicists.

Pekeris, C.L. \& Jarosch, H., 1958. The free oscillations of the earth. In Contributions in Geophysics in Honor of Beno Gutenberg, pp. 171-192, eds Benioff, H., Ewing, M., Howell, B. \& Press, F., Pergamon, New York. Scherbaum, F., Klaus-Hinzen, G. \& Ohrnberger, M., 2003. Determination of shallow shear wave velocity profiles in the Cologne, 
PAS 1988-2003 Mo $>5.0 \mathrm{e}+18$ f_width $=0.0100$ Scheme 2

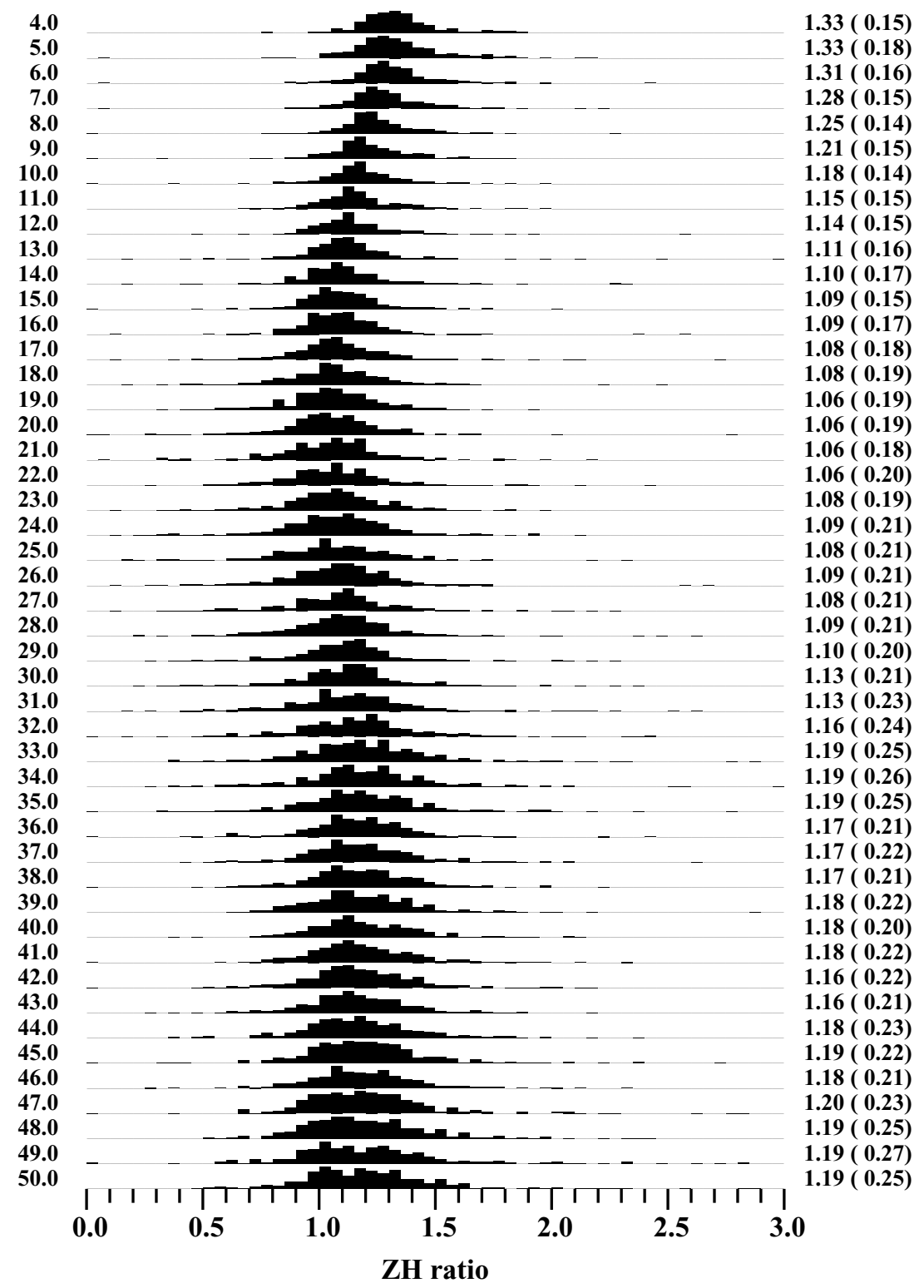

Figure 10. (Continued.)

Germany area using ambient vibrations, Gephys. J. Int., 152, 597612.

Takeuchi, H., 1959. Torsional oscillations of the Earth and some related problems, Geophys. J. R. astr. Soc., 2, 89-100.

Takeuchi, H. \& Saito, M., 1972. Seismic surface waves, In Methods in Computational Physics, Vol. 11, pp. 217-295, Academic Press, New York.

Tanimoto, T., 1988. The 3D shear wave structure in the mantle by overtone waveform inversion- II. Inversion of X-waves, R-waves and G-waves, Geophys. J. R. astr. Soc., 93, 321-334.

Tanimoto, T. \& Alvizuri, C., 2006. Inversion of the HZ ratio of micro- seisms for S-wave velocity in the crust, Geophys. J. Int., 165, 323-335, doi:10.1111/j.1365-246X.2006.02905.x.

Tanimoto, T. \& Rivera, L., 2005. Prograde Rayleigh wave particle motion, Geophys. J. Int., 162, 399-405.

Woodhouse, J.H., 1976. On Rayleigh's Principle, Geophys. J. R. astr. Soc., 46, 11-22.

Woodhouse, J.H. \& Dahlen, F.A., 1978. The effect of a general apherical perturbation on the free oscillations of the Earth, Geophys. J. R. astr. Soc., 53, 335-354.

Yamanaka, H., Takemura, M., Ishida, H. \& Niwa, M., 1994. Bull. seism. Soc. Am., 84, 1831-1841. 


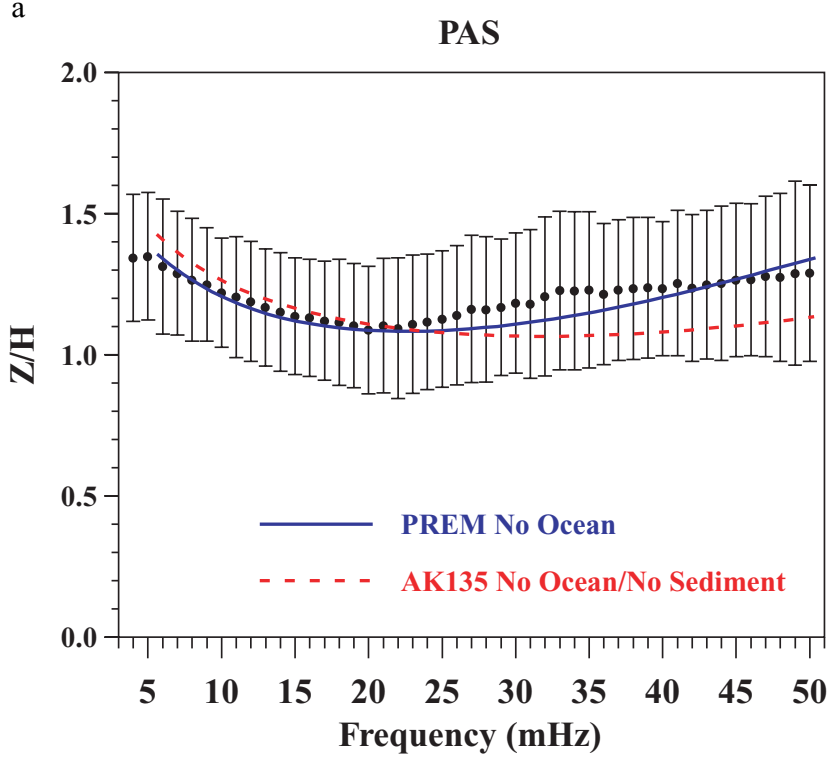

$\mathrm{b}$

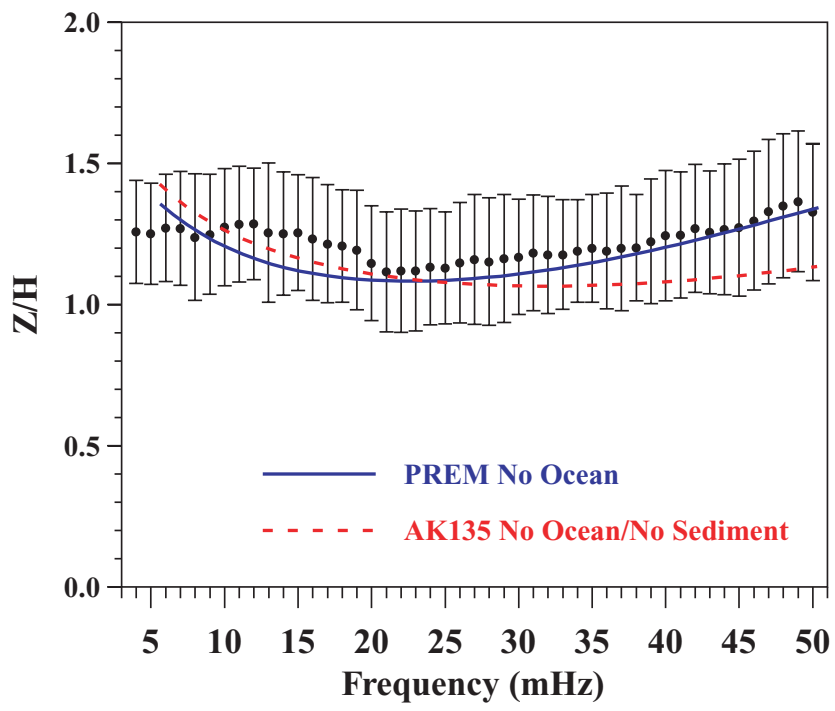

Figure 11. (a)-(e) Measured ZH ratios for five stations in Southern California. Theoretical curves for two earth models are shown for comparison. Deviations from theoretical curves occur in different frequency ranges for different stations, indicating information for local structure buried in this data (ZH ratio). c
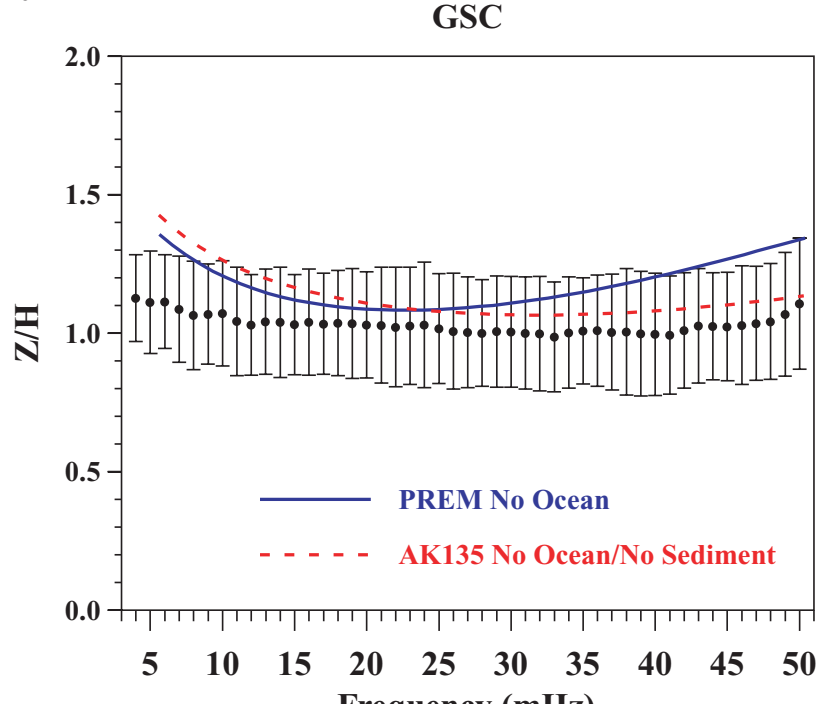
Frequency $(\mathrm{mHz})$

d

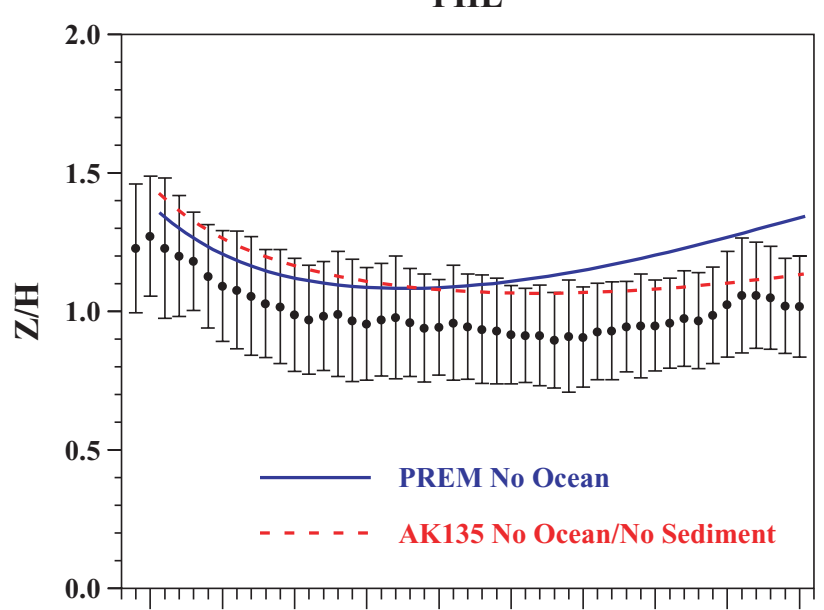

$\begin{array}{llllllllll}5 & 10 & 15 & 20 & 25 & 30 & 35 & 40 & 45 & 50\end{array}$ Frequency $(\mathrm{mHz})$

e

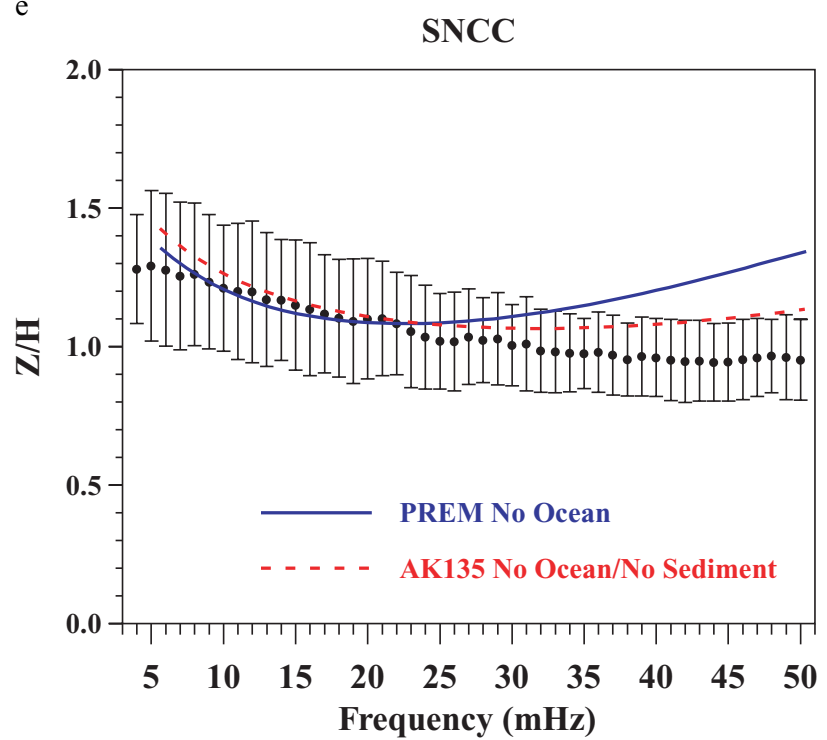

Figure 11. (Continued.) 